\title{
Panobinostat for the treatment of multiple myeloma: the evidence to date
}

\author{
This article was published in the following Dove Press journal: \\ Journal of Blood Medicine \\ 8 October 2015 \\ Number of times this article has been viewed
}

\author{
Hanna Bailey' \\ David D Stenehjem ${ }^{1,2}$ \\ Sunil Sharma' \\ 'Huntsman Cancer Institute, \\ ${ }^{2}$ Department of Pharmacotherapy, \\ Pharmacotherapy Outcomes Research \\ Center, University of Utah, Salt Lake \\ City, UT, USA
}

\begin{abstract}
Multiple myeloma is a malignancy involving plasma cell proliferation within the bone marrow. Survival of patients diagnosed with myeloma has significantly improved in the last decade, following the approval of novel agents. Despite great strides achieved in the management of multiple myeloma, it is still considered an incurable disease as the majority of patients relapse after initiation of therapy. Additionally, the duration of response generally decreases with an increasing number of therapy lines. The need to overcome resistance to therapy dictates research into more potent agents and those with novel mechanisms of action. A therapeutic option for relapsed/refractory myeloma includes histone deacetylase inhibition. Various histone deacetylase inhibitors, including the newly approved panobinostat, are currently under evaluation in this setting. Panobinostat for multiple myeloma is used in combination with other potent therapeutic agents, such as proteasome inhibitors and steroids. Ongoing research evaluating other panobinostat-containing regimens will provide additional insight into its place in myeloma management.
\end{abstract}

Keywords: panobinostat, LBH589, multiple myeloma, relapsed, HDAC inhibitor

\section{Introduction}

Multiple myeloma involves malignant proliferation of plasma cells within the bone marrow and elevation in levels of monoclonal immunoglobulin in the blood or urine, resulting in organ damage. ${ }^{1}$ Increased serum calcium levels, renal insufficiency, anemia, and bone lesions frequently accompany multiple myeloma at presentation and throughout the disease. Being the second most common hematologic malignancy in the USA, there will be $\sim 26,850$ newly diagnosed cases of multiple myeloma in 2015. Additionally, 11,240 deaths due to multiple myeloma are predicted to occur in $2015 .^{2}$

Multiple myeloma is generally sensitive to multiple cytotoxic agents, both in the initial and relapsed settings. However, responses are frequently short lived, requiring the need for new therapeutic agents and more effective combination regimens. Currently, the management of multiple myeloma is rapidly evolving. In the last decade, great progress has been achieved following advances in autologous stem cell transplantation and approval of new drugs, including proteasome inhibitors and immunomodulatory agents. ${ }^{3}$ As a result, there was a significant improvement in response rates leading to improved myeloma survival, especially in the younger patient population. ${ }^{4}$ In fact, 5-year relative survival rates have nearly doubled, increasing from $27 \%$ to $47 \%$ between 1987-1989 and 2004-2010, respectively. ${ }^{2}$

Despite recent advancements in management, multiple myeloma remains an incurable disease, and the vast majority of patients eventually develop treatment resistance. ${ }^{5}$
Correspondence: Hanna Bailey Huntsman Cancer Institute, UT/US, 1950 Circle of Hope, Suite N2545, Salt Lake City, UT 84I I2, USA $\mathrm{Tel}+\mathrm{l} 8012134258$

Fax + 8015853102

Email hanna.bailey@hci.utah.edu (c) (i) (5) $\odot 215$ Bailey et al. This work is published by Dove Medical Press Limited, and licensed under Creative Commons Attribution - Non Commercial (unported, v3.0) License. The full terms of the License are available at http://creativecommons.org/licenses/by-nc/3.0/. Non-commercial uses of the work are permitted without any further permission frove Medical Press Limited, provided the work is properly attributed. Permissions beyond the scope of the License are administered by Dove Medical Press Limited. Information on how to request permission may be found at: http://www.dovepress.com/permissions.php 
Furthermore, the duration of response generally decreases with an increasing number of therapy lines. ${ }^{6}$ Due to the resistant nature of the disease, there is a growing need to introduce other proteasome inhibitors and immunomodulatory agents as well as agents with a novel mechanism of action, effective in later stages of myeloma. Increasing knowledge of bone marrow microenvironment and molecular aberrations present in multiple myeloma has led to new drug development and other combination therapies for the management of relapsed and/or refractory disease. ${ }^{7}$ In this article, we review an alternative therapeutic target in multiple myeloma and the evidence outlining the use of panobinostat as part of combination therapy in the management of relapsed and refractory disease.

\section{Histone deacetylase inhibition}

Two groups of enzymes are involved in a form of epigenetic modification involving protein acetylation. Histone acetylases and histone deacetylases (HDACs) act in opposition to each other to control acetylation levels of both histone and nonhistone proteins. ${ }^{8}$ The main function of histones is to compact DNA into nucleosomes, which are the basic subunits of DNA chromatin structure. Proper histone formation is important for such cellular processes as DNA repair, gene expression, and gene regulation. Acetylation of lysine residues on histones and some nonhistone proteins by histone acetylases results in relaxation of DNA chromatin structure allowing for subsequent gene transcription. Conversely, removal of acetyl groups by HDAC enzymes causes compacted chromatin structure, inaccessibility of DNA for transcription, and ultimately gene silencing. ${ }^{9}$

An imbalance between histone acetylation and deacetylation has been implicated in cancer development. ${ }^{10}$ The loss of acetylation is reported as a common molecular event in human cancers, including multiple myeloma, often occurring in earlier stages of tumorigenesis. ${ }^{11}$ This evidence may indicate the potential critical role of HDACs in cancer initiation and progression, pointing to an alternative target for anticancer therapies.

HDACs are involved in many critical processes in myeloma cell lines, including gene transcription, progression of cell cycle, DNA repair, and protein formation and folding. ${ }^{5}$ In addition, myeloma cells produce a significant number of misfolded proteins, specifically immunoglobulins, resulting in the need to effectively degrade excess toxic products through proteasome and aggresome pathways. ${ }^{12}$ It is not surprising, therefore, that proteasome inhibitors play a central role in the management of various stages of multiple myeloma by causing cell death of malignant cells. ${ }^{1}$ However, proteasome blockade does not fully inhibit cellular catabolism of proteins. A compensatory activation of the aggresome pathway following administration of proteasome inhibitors leads to continued autophagy of protein degradation products and inhibition of apoptosis in tumor cells. Therefore, induction of the aggresome pathway may partially explain the acquired resistance of proteasome inhibition. ${ }^{13}$ Recently, HDAC6 has been found to play an important role in the aggresome-autophagy pathway through interaction with dynein, which targets protein aggregates to the autophagosome for destruction. ${ }^{14}$ As a result, HDAC inhibition has become an alternative therapeutic strategy in multiple myeloma management.

Various HDAC inhibitors have been tested in preclinical models of multiple myeloma. Effective HDAC inhibition results in multiple cellular responses, specifically cell cycle arrest, inhibition of cellular growth, DNA damage, interference with activity of the aggresome pathway, and induction of apoptosis. ${ }^{15-17}$ Additionally, HDAC inhibitors have been studied in combination with other conventional and novel agents in preclinical studies of multiple myeloma. ${ }^{18}$

Panobinostat (LBH589) is a pan-deacetylase inhibitor belonging to hydroxamic acid family of compounds and is active against class I, II, and IV HDAC enzymes. ${ }^{19}$ Panobinostat has potent cytotoxic activity against tumor cells, while displaying minimal toxicity against normal cells. ${ }^{19}$ It inhibits the removal of acetyl groups by HDAC enzymes, leading to maintenance of acetylation of histone and nonhistone proteins. As a result, accumulation of histones and other proteins occurs, causing cell cycle arrest and apoptosis of cancer cells of various cancer types. Panobinostat has demonstrated potent preclinical activity in several hematologic malignancies such as acute myeloid leukemia, cutaneous T-cell lymphoma, chronic myeloid leukemia, and multiple myeloma, as well as solid tumors, including prostate, breast, and pancreatic cancers. ${ }^{20,21}$

Panobinostat has demonstrated synergy with several agents already used in the treatment of multiple myeloma. The strongest evidence exists for combination regimens containing proteasome inhibitors. Panobinostat is thought to augment the activity of proteasome inhibitors through inhibition of interaction between myeloma cells and tumor microenvironment and by blocking activation of the aggresome pathway, an alternative degradation route for misfolded and unfolded proteins. $^{22}$ Panobinostat leads to hyperacetylation of $\alpha$-tubulin and HDAC6 inhibition, which results in disruption of transportation of misfolded proteins for autophagy, ultimately 
targeting the cell for apoptosis. ${ }^{19}$ Panobinostat, therefore, blocks the rescue pathway of protein degradation developed by myeloma cells. These cooperative mechanisms of synergy suggest chemosensitization to proteasome inhibition by panobinostat, with a potential benefit of overcoming resistance to existing therapeutic options for multiple myeloma. However, it is currently not proven whether HDAC6 inhibition is the pathway responsible for the activity of HDAC inhibitors in the treatment of multiple myeloma. Additionally, panobinostat may have the ability to potentiate antitumor activity of steroids and immunomodulatory agents, such as thalidomide and lenalidomide. ${ }^{23}$ The aforementioned potential for synergy has provided the rationale for the use of panobinostat in multiple myeloma therapy, especially in combination with other potent therapeutic agents.

\section{Clinical efficacy}

The efficacy of oral panobinostat has been assessed in multiple myeloma, both as a single agent and as part of combination therapy with other agents having known activity in myeloma (Table 1). Single-agent panobinostat activity was studied in a Phase Ia/II study, which included patients with various hematologic malignancies, such as multiple myeloma. Panobinostat was administered once a day, three times per week, every week or every other week in a 28-day cycle. Based on the dose escalation phase, 40 and $60 \mathrm{mg}$ doses were recommended for the expansion phase for weekly and biweekly administration, respectively. Modest activity was noted in six patients with multiple myeloma, with one patient achieving a partial response (PR). The most significant grade 3-4 adverse events noted in the study were

Table I Summary of clinical trials of panobinostat in multiple myeloma

\begin{tabular}{|c|c|c|c|c|c|c|}
\hline Trials & Study design & Patients (n) & $\begin{array}{l}\text { Median } \\
\text { age (years) }\end{array}$ & Interventions & Efficacy & $\begin{array}{l}\text { Adverse events } \\
\text { (grade 3-4) }\end{array}$ \\
\hline DeAngelo et $\mathrm{al}^{24}$ & $\begin{array}{l}\text { Open-label, } \\
\text { single-arm, } \\
\text { Phase la/ll }\end{array}$ & 6 patients & - & PAN & ORR: $16.7 \%$ & $\begin{array}{l}\text { Thrombocytopenia (4I.5\%) } \\
\text { Fatigue (2I\%) } \\
\text { Neutropenia (2I\%) }\end{array}$ \\
\hline Wolf et $\mathrm{al}^{25}$ & $\begin{array}{l}\text { Open-label, } \\
\text { single-arm, } \\
\text { Phase II }\end{array}$ & 38 patients & 61 & PAN & ORR: $2.6 \%$ & $\begin{array}{l}\text { Neutropenia (2I.1\%) } \\
\text { Thrombocytopenia (18.4\%) }\end{array}$ \\
\hline San-Miguel et $\mathrm{al}^{26}$ & $\begin{array}{l}\text { Open-label, } \\
\text { single-arm, } \\
\text { Phase lb }\end{array}$ & $\begin{array}{l}\text { Escalation phase: } \\
47 \text { patients } \\
\text { Expansion phase: } \\
\text { I5 patients }\end{array}$ & 62 & $\begin{array}{l}\mathrm{PAN} / \mathrm{BTZ} \pm \mathrm{DEX} \\
\text { (all patients in } \\
\text { expansion phase) }\end{array}$ & $\begin{array}{l}\text { Escalation phase: } \\
\text { ORR: } 52.9 \% \\
\text { Expansion phase: } \\
\text { ORR: } 73.3 \% \text { (MTD dose) }\end{array}$ & $\begin{array}{l}\text { Escalation phase: } \\
\text { Thrombocytopenia (85.1\%) } \\
\text { Neutropenia (63.8\%) } \\
\text { Asthenia }(29.8 \%) \\
\text { Expansion phase: } \\
\text { Thrombocytopenia }(66.7 \%) \\
\text { Neutropenia (46.7\%) } \\
\text { Fatigue }(20 \%)\end{array}$ \\
\hline Richardson et $\mathrm{al}^{27,28}$ & $\begin{array}{l}\text { Open-label, } \\
\text { single-arm, } \\
\text { Phase II }\end{array}$ & 55 patients & 61 & PAN/BTZ/DEX & $\begin{array}{l}\text { ORR: } 34.5 \% \\
\text { PFS: } 5.4 \text { months } \\
\text { OS: } 17.5 \text { months }\end{array}$ & $\begin{array}{l}\text { Thrombocytopenia (63.6\%) } \\
\text { Diarrhea }(20 \%) \\
\text { Fatigue }(20 \%) \\
\text { Neutropenia }(14.6 \%)\end{array}$ \\
\hline San-Miguel et $\mathrm{al}^{29}$ & $\begin{array}{l}\text { Placebo- } \\
\text { controlled, } \\
\text { double-blind, } \\
\text { Phase III }\end{array}$ & $\begin{array}{l}387 \text { patients } \\
\text { (PAN/BTZ/DEX) } \\
381 \text { patients } \\
\text { (BTZ/DEX/ } \\
\text { placebo) }\end{array}$ & 63 & PAN/BTZ/DEX & $\begin{array}{l}\text { PFS: I } 2 \text { vs } 8 . I \text { months } \\
(P<0.000 \text { I }) \\
\text { OS: } 33.6 \text { vs } 30.4 \text { months } \\
(P=0.26) \\
\text { ORR: } 60.7 \% \text { vs } 54.6 \% \\
(P=0.09)\end{array}$ & $\begin{array}{l}\text { Thrombocytopenia (68\%) } \\
\text { Neutropenia (35\%) } \\
\text { Diarrhea (25\%) } \\
\text { Fatigue }(24 \%) \\
\text { Peripheral neuropathy (18\%) }\end{array}$ \\
\hline Berdeja et $\mathrm{al}^{31}$ & $\begin{array}{l}\text { Open-label, } \\
\text { single-arm, } \\
\text { Phase I, II }\end{array}$ & $\begin{array}{l}\text { Escalation phase: } \\
\text { I } 3 \text { patients } \\
\text { Expansion phase: } \\
3 \text { I patients }\end{array}$ & 66 & PAN/CFZ & $\begin{array}{l}\text { ORR: } 67 \% \\
\text { PFS: } 7.7 \text { months }\end{array}$ & $\begin{array}{l}\text { Thrombocytopenia (38\%) } \\
\text { Neutropenia (21\%) } \\
\text { Fatigue ( } 1 \% \text { ) }\end{array}$ \\
\hline Berenson et $\mathrm{al}^{32}$ & $\begin{array}{l}\text { Open-label, } \\
\text { single-arm, } \\
\text { Phase I, II }\end{array}$ & 40 patients & 65 & PAN/MEL & ORR: $7.5 \%$ & $\begin{array}{l}\text { Neutropenia (30.8\%) } \\
\text { Thrombocytopenia (23.I\%) }\end{array}$ \\
\hline Offidani et al ${ }^{33}$ & $\begin{array}{l}\text { Open-label, } \\
\text { single-arm, } \\
\text { Phase II }\end{array}$ & 31 patients & 73 & $\begin{array}{l}\text { PAN/MEL/PRED/ } \\
\text { THAL }\end{array}$ & ORR: $38.5 \%$ & $\begin{array}{l}\text { Neutropenia (7I\%) } \\
\text { Thrombocytopenia (35.5\%) }\end{array}$ \\
\hline
\end{tabular}

Abbreviations: BTZ, bortezomib; CFZ, carfilzomib; DEX, dexamethasone; MEL, melphalan; MTD, maximum-tolerated dose; ORR, overall response rate; OS, overall survival; PAN, panobinostat; PFS, progression-free survival; PRED, prednisone; THAL, thalidomide. 
thrombocytopenia (41.5\%), fatigue (21\%), and neutropenia (21\%). ${ }^{24}$ Another single-agent study was a Phase II study of patients with heavily pretreated relapsed/refractory (RR) multiple myeloma. The median number of prior lines of therapy was five. In this trial, $20 \mathrm{mg}$ of panobinostat was given by mouth three times per week, every week in a 21-day cycle. Again, single-agent activity of panobinostat was modest, with one patient $(2.6 \%)$ achieving PR and one other patient (2.6\%) developing minimal response to therapy. However, these responses were durable and lasted 19 and 28 months, respectively. Similar to the previous study, hematologic toxicities were the most common grade 3-4 adverse events (neutropenia $21.1 \%$, thrombocytopenia 18.4\%). ${ }^{25}$

The combination of bortezomib and panobinostat was investigated in a Phase Ib trial of patients with RR multiple myeloma. During the dose-escalation phase, panobinostat was administered orally three times per week, every week in combination with intravenous (IV) bortezomib on days $1,4,8$, and 11 of a 21-day cycle. Dexamethasone (20 mg orally) was given starting in cycle 2 based on the investigator's discretion. Maximum tolerated doses (MTDs) of panobinostat and bortezomib were determined to be $20 \mathrm{mg}$ and $1.3 \mathrm{mg} / \mathrm{m}^{2}$, respectively, for the dose-expansion phase of the trial, with panobinostat administered during weeks 1 and 2 only to allow for platelet recovery and to minimize dose interruptions. Dexamethasone was included in therapy for all patients during this phase, as preclinical data demonstrated greater antitumor activity with triple combination therapy compared to dual therapy. ${ }^{23}$ Overall response rates (ORRs) were $52.9 \%$ and $73.3 \%$ in the dose-escalation phase at MTD and dose-expansion phase, respectively. Of note, the ORR among bortezomib-refractory patients was $26.3 \%$, with $42.1 \%$ of patients experiencing at least a minimal response. In line with previous trials, hematologic toxicities were the most common adverse events observed. The doseexpansion phase was noted to have a lower rate of grade 3-4 thrombocytopenia compared to the dose-escalation phase (66.7\% vs $85.1 \%$ ) with improved platelet recovery and no platelet-driven discontinuation of panobinostat. One patient developed clinically significant QTc prolongation (1.6\%). This trial established the dosing regimen of panobinostat, bortezomib, and dexamethasone combination therapy for evaluation in larger Phase II and III trials. ${ }^{26}$

PANORAMA 2 study was an open-label, two-stage Phase II trial evaluating panobinostat, bortezomib, and dexamethasone combination in patients with relapsed and bortezomib-refractory multiple myeloma. The median number of prior lines of therapy was four. Phase I treatment included eight 21-day cycles of panobinostat $20 \mathrm{mg}$ orally thrice weekly during weeks 1 and 2; bortezomib $1.3 \mathrm{mg} / \mathrm{m}^{2} \mathrm{IV}$ twice weekly during weeks 1 and 2; and oral dexamethasone $20 \mathrm{mg}$ on days of and after bortezomib administration. Patients showing clinical benefit were allowed to proceed to Phase II, which consisted of 6-week cycles with panobinostat thrice weekly during weeks 1, 2, 4, and 5; bortezomib once a week during weeks 1, 2, 4, and 5; and dexamethasone on the days of and after bortezomib administration. Treatment in Phase II was continued until disease progression or unacceptable toxicity. One complete response and 18 PRs were seen out of the 55 patients participating in the study. Therefore, the ORR was $34.5 \%$. Additionally, ten more patients developed a minimal response for a total clinical benefit rate of $52.5 \%$. The median progression-free survival (PFS) was 5.4 months, with a median overall survival (OS) of 17.5 months. In 19 patients with PR, median PFS and median OS were 7.6 and 25.2 months, respectively. ${ }^{27,28}$ Overall, this regimen was well tolerated. The most common grade 3-4 adverse event was thrombocytopenia (63.6\%); however, it did not require treatment discontinuation. Peripheral neuropathy observed in this trial was mild, with only one patient developing grade $\geq 3$ toxicity. This study established the role of panobinostat in combination with bortezomib and dexamethasone for the treatment of bortezomib-refractory multiple myeloma, with a manageable side-effect profile. ${ }^{27}$

Recently, the results of PANORAMA 1, a randomized placebo-controlled Phase III trial, were published. This was a single largest trial of panobinostat use in multiple myeloma to date, enrolling 768 patients. The combination of panobinostat, bortezomib, and dexamethasone was compared to bortezomib and dexamethasone alone in patients with RR multiple myeloma having received 1-3 prior lines of therapy. The trial consisted of two phases, with regimens identical to PANORAMA 2 study with the exception of a maximum of four cycles of treatment in Phase II. Compared to placebo, the median PFS was increased in the panobinostat arm (12 vs 8.1 months; hazard ratio: $0.63 ; 95 \%$ confidence interval: $0.52-0.76 ; P<0.0001)$. Median OS data is not mature, but is currently reported at 33.6 months in the panobinostat group vs 30.4 months in those receiving placebo (hazard ratio: 0.87 , 95\% confidence interval: $0.69-1.1, P=0.26)$. Although ORRs were not significantly different between the groups $(60.7 \% \mathrm{vs}$ $54.6 \%, P=0.09$ ), more patients in the panobinostat group achieved complete or near complete response to therapy (27.6\% vs $15.7 \%, P=0.00006$ ). Median duration of response was 13.1 vs 10.9 months in the panobinostat vs placebo groups, respectively. The safety profile of panobinostat, bortezomib, 
and dexamethasone combination is comparable to the results reported in PANORAMA 2 study (Table 1). The most common grade 3-4 toxicities in panobinostat arm were thrombocytopenia (68\%), neutropenia (35\%), diarrhea (25\%), fatigue (24\%), and peripheral neuropathy (18\%). Five patients in the panobinostat arm were reported to have a QTc interval $>480 \mathrm{~ms}$, but not higher than $500 \mathrm{~ms}$. Three patients in the panobinostat group had QTc interval increases $>60 \mathrm{~ms}$ from baseline compared to four patients in placebo group. T-wave changes and $\mathrm{ST}-\mathrm{T}$ segment changes were more common in the panobinostat group, but were deemed to be asymptomatic. The results of this trial have demonstrated the additional benefit of panobinostat in improving PFS in RR multiple myeloma when added to bortezomib and dexamethasone. ${ }^{29}$ The effect of this combination on OS will be updated after the planned 415 deaths occur.

Previous trials of panobinostat and bortezomib combination have prompted investigation of panobinostat safety and efficacy with carfilzomib, a second-generation proteasome inhibitor effective in multiple myeloma with a lower incidence of peripheral neuropathy compared to bortezomib. ${ }^{30}$ Currently, a randomized Phase III trial is exploring comparative efficacy of carfilzomib and bortezomib (ClinicalTrials. gov identifier: NCT01568866). Patients with RR multiple myeloma after at least one line of therapy were enrolled to receive carfilzomib and panobinostat combination in a Phase I/II study. The median number of lines of therapy prior to study accrual was five. The regimen consisted of oral panobinostat administered on days 1, 3, 5, 15, 17, and 19, whereas IV carfilzomib was given on days $1,2,8,9,15$, and 16 of a 28-day cycle. During the dose-escalation phase, no dose-limiting toxicities were encountered, and the expansion phase doses were set at $30 \mathrm{mg}$ and $20 / 45 \mathrm{mg} / \mathrm{m}^{2}$ for panobinostat and carfilzomib, respectively, with the lower dose of carfilzomib administered on days 1 and 2 of cycle 1 only. The ORR was $67 \%$, and a clinical benefit was noted in $79 \%$ of patients. Prior therapies did not seem to have an influence on response rates. Median PFS was noted to be 7.7 months. Median OS data is not yet mature. Adverse events were the cause of therapy discontinuation in $9 \%$ of patients. Diarrhea, nausea and vomiting, and thrombocytopenia were the most frequently encountered toxicities. ${ }^{31}$

Panobinostat has been reported in literature to have synergistic activity with melphalan, an alkylating agent, in multiple myeloma cell lines. A Phase I/II study has been performed combing panobinostat and oral melphalan. Due to toxicity issues, the dosing schema was modified several times during the study, which led to four different treatment regimens.
Overall, three patients responded (two very good PR and one PR) while receiving a more intensive regimen (panobinostat $20 \mathrm{mg}$ thrice a week continuously and melphalan $0.05 \mathrm{mg} / \mathrm{kg}$ on days 1,3 , and 5) at the expense of increased toxicity. MTD was determined to be $20 \mathrm{mg}$ of panobinostat and $0.05 \mathrm{mg} / \mathrm{kg}$ of melphalan given on days 1,3 , and 5 of a 28-day cycle. Although this regimen was better tolerated, no responses were observed with this dosing schedule. ${ }^{32}$ Finally, panobinostat was evaluated in combination with melphalan, prednisone, and thalidomide in a Phase II study of patients with RR multiple myeloma. The treatment regimen consisted of oral melphalan at a dose of $0.18 \mathrm{mg} / \mathrm{kg}$ on days $1-4$, prednisone given as $1.5 \mathrm{mg} / \mathrm{kg}$ on days $1-4$, thalidomide $50 \mathrm{mg} / \mathrm{d}$ throughout the cycle, and escalating doses of panobinostat with a range of 10-20 mg three times weekly for 3 weeks of a 28-day cycle. MTD was not established in this trial due to significant toxicities, with patients receiving between 10 and $15 \mathrm{mg}$ of panobinostat. Dose-limiting toxicities included grade 3-4 neutropenia (71\%) and thrombocytopenia (35.5\%). ${ }^{33}$ As a result, panobinostat and melphalan combination has not produced encouraging results due to relevant toxicity issues without significant antimyeloma benefit.

Panobinostat is being evaluated as part of other combination regimens in multiple myeloma. It is currently investigated in various combinations with lenalidomide/ thalidomide, bortezomib, and dexamethasone (ClinicalTrials. gov identifiers: NCT01965353, NCT02145715). A trial combining panobinostat, ixazomib (MLN9708), a new proteasome inhibitor, and dexamethasone is underway (ClinicalTrials.gov identifier: NCT02057640). Additionally, panobinostat and everolimus, a mammalian target of rapamycin inhibitor, are being evaluated for the treatment of hematologic malignancies, including RR multiple myeloma (ClinicalTrials.gov identifier: NCT00918333).

As mentioned previously, panobinostat is a pandeacetylase inhibitor, affecting class I, II, and IV HDAC enzymes, including HDAC6. Recently, there has been a growing interest to develop next-generation HDAC6selective HDAC inhibitors. Ricolinostat (ACY-1215) is a selective HDAC6 inhibitor that is currently being evaluated in the treatment of multiple myeloma and lymphoma. Specifically targeting HDAC6, as opposed to other enzymes in the HDAC family, may potentially lead to fewer serious adverse effects while maintaining efficacy. ${ }^{34}$

\section{Adverse effects}

Oral panobinostat is generally well tolerated, with the most frequent adverse events observed in clinical trials being 
thrombocytopenia, neutropenia, fatigue, diarrhea, electrolyte abnormalities, and increased creatinine. ${ }^{24-27,29,31-33}$ The time to onset of platelet nadir is reported between 12 and 15 days after the start of the cycle. ${ }^{24}$ Therefore, multiple regimens are using 21-day cycles with panobinostat omitted during week $3 .^{26,27,29}$ In PANORAMA 1 study, serious adverse events were observed in $60 \%$ of patients in panobinostat group as opposed to $42 \%$ of patients receiving placebo. ${ }^{29}$ Thirty-six percent of patients in the panobinostat arm discontinued therapy due to adverse events vs $20 \%$ on placebo. The most common side effects leading to discontinuation of therapy in patients receiving panobinostat were diarrhea (4\%), peripheral neuropathy (4\%), asthenia or fatigue $(6 \%)$, thrombocytopenia (2\%), and pneumonia (1\%). Grade 3-4 hemorrhage was observed in $4 \%$ of patients while on panobinostat therapy compared to $2 \%$ in the placebo group.

One of the most clinically significant adverse events experienced by patients is diarrhea. Panobinostat prescribing information has a boxed warning, describing a $25 \%$ incidence of grade 3-4 diarrhea. ${ }^{35}$ Patients should be monitored for symptoms of diarrhea, with initiation of antidiarrheal agents and interruption of panobinostat therapy as necessary. ${ }^{35}$ Another boxed warning describes a potential risk of severe and fatal cardiac ischemic events, electrocardiogram (ECG) changes, and severe arrhythmias. Originally formulated as an IV agent, panobinostat was associated with QTc prolongation and cardiac arrhythmias. ${ }^{36}$ This resulted in discontinuation of the IV form. Still, cardiac abnormalities remain a concern with oral panobinostat, although the incidence of these adverse events is significantly reduced with the oral formulation. ${ }^{29}$ It is recommended to perform baseline ECG and electrolytes and repeat these tests as necessary throughout treatment. In the meantime, providers should avoid concurrent administration of other QT prolonging medications. ${ }^{35}$

Finally, panobinostat carries a potential risk for teratogenicity as seen in preclinical study. Female patients should be instructed to avoid pregnancy while on therapy with panibinostat. ${ }^{35}$

\section{Implications for clinical practice}

Panobinostat $\left(\right.$ Farydak $^{\circledR}$, Novartis Pharmaceuticals Corporation, East Hanover, NJ, USA) in combination with bortezomib and dexamethasone received accelerated approval from US Food and Drug Administration (FDA) on February 23, 2015, for the treatment of multiple myeloma in patients with a history of at least two prior lines of therapy, including bortezomib and an immunomodulatory agent.
The recommended dose of panobinostat is $20 \mathrm{mg}$ by mouth with or without food on days 1, 3, and 5 during weeks 1 and 2 of a 21-day cycle for up to 8 cycles, with an additional 8 cycles in patients demonstrating clinical benefit. ${ }^{35}$

Patients receiving panobinostat should be carefully monitored for adverse events using complete blood count, ECG, and complete metabolic panel. As mentioned in boxed warnings, panobinostat is associated with the development of potentially severe diarrhea and a small, but existing, risk of QTc prolongation and arrhythmias. As a result, FDA approved panobinostat with a risk evaluation and mitigation strategy program in place in order to educate providers and patients regarding the potential toxicities of panobinostat. ${ }^{35}$

Other important clinical considerations health care providers should be aware of include dosing in hepatic impairment and drug interactions. Hepatic impairment may result in increased panobinostat exposure. Reductions in plasma clearance with mild and moderate hepatic dysfunction were $30 \%$ and $51 \%$, respectively. ${ }^{37}$ The corresponding increase in panobinostat exposure with mild and moderate hepatic impairment was $43 \%$ and $105 \%$, respectively. ${ }^{37}$ The starting dose of panobinostat is $15 \mathrm{mg}$ in patients with mild hepatic dysfunction, whereas patients with moderate hepatic failure should be initiated at doses of $10 \mathrm{mg}$. Severe hepatic impairment precludes treatment. In addition, panobinostat may be associated with clinically significant drug interactions due to various effects of CYP isoenzymes and P-glycoprotein. Panobinostat is a strong substrate of CYP3A4 and P-glycoprotein, leading to potential drug interactions with medications that are strong CYP3A inducers or inhibitors. In fact, panobinostat should be empirically dose reduced to $10 \mathrm{mg}$ with concomitant administration of strong CYP3A4 inhibitors, such as azole antifungals and protease inhibitors. Furthermore, providers need to advise patients to avoid star fruit, grapefruit, and grapefruit juice, which are known CYP3A4 inhibitors. Finally, panobinostat is a moderate CYP2D6 inhibitor and has the potential to increase concentrations of certain medications, including antidepressants, some $\beta$-blockers, and dextromethorphan for example. Therefore, patients should be regularly monitored for any potential drug interactions. ${ }^{35}$

\section{Conclusion}

Despite significant advances in multiple myeloma management, it still remains an incurable disease. There is a growing need to overcome resistance to therapy by developing newer generations of currently available therapeutic agents as well 
as agents with entirely novel mechanisms of action. HDAC overexpression has been implicated in myeloma initiation and progression. Panobinostat, a potent HDAC inhibitor, has been recently approved for the treatment of multiple myeloma following at least two prior lines of therapy. Synergy in therapeutic activity has been demonstrated between bortezomib and panobinostat, including in those with bortezomib-refractory disease. Although approved for RR multiple myeloma, panobinostat in combination with steroids and a proteasome inhibitor is likely to be utilized in earlier lines of myeloma management. Additionally, multiple other combinations of panobinostat and antimyeloma agents are being evaluated in clinical trials, which will assist in defining the role of this agent in multiple myeloma therapy.

\section{Disclosure}

The authors report no conflicts of interest in this work.

\section{References}

1. Gozzetti A, Candi V, Papini G, Bocchia M. Therapeutic advancements in multiple myeloma. Front Oncol. 2014;4:241.

2. Siegel RL, Miller KD, Jemal A. Cancer statistics, 2015. CA Cancer J Clin. 2015;65:5-29.

3. Mateos MV, Ocio EM, San Miguel JF. Novel generation of agents with proven clinical activity in multiple myeloma. Semin Oncol. 2013;40(5): 618-633.

4. Brenner H, Gondos A, Pulte D. Recent major improvement in long-term survival in younger patients with multiple myeloma. Blood. 2008;111: 2521-2526.

5. Orlowski RZ. Novel agents for multiple myeloma to overcome resistance in Phase III clinical trials. Semin Oncol. 2013;40(5):634-651.

6. Kumar SK, Therneau TM, Gertz MA, et al. Clinical course of patients with relapsed multiple myeloma. Mayo Clin Proc. 2004;79:867-874.

7. Hideshima T, Anderson KC. Molecular mechanisms of novel therapeutic approaches for multiple myeloma. Nat Rev Cancer. 2002; 2(12):927-937.

8. Khan O, La Thangue NB. HDAC inhibitors in cancer biology: emerging mechanisms and clinical applications. Immunol Cell Biol. 2012;90(1): 85-94.

9. Maes K, Menu E, Van Valckenborgh E, Van Riet I, Vanderkerken K, De Bruyne E. Epigenetic modulating agents as a new therapeutic approach in multiple myeloma. Cancers. 2013;5(2):430-461.

10. Ropero S, Esteller M. The role of histone deacetylases (HDACs) in human cancer. Mol Oncol. 2007;1(1):19-25.

11. Fraga MF, Ballestar E, Villar-Garea A, et al. Loss of acetylation at Lys 16 and trimethylation at Lys 20 of histone $\mathrm{H} 4$ is a common hallmark of human cancer. Nat Genet. 2005;37:391-400.

12. Aronson LI, Davies FE. Danger: protein overload. Targeting protein degradation to treat myeloma. Haematologica. 2012;97(8):1119-1130.

13. Kale AJ, Moore BS. Molecular mechanisms of acquired proteasome inhibitor resistance. J Med Chem. 2012;55(23):10317-10327.

14. Yan J. Interplay between HDAC6 and its interacting partners: essential roles in the aggresome-autophagy pathway and neurodegenerative diseases. DNA Cell Biol. 2014;33(9):567-580.

15. Lavelle D, Chen YH, Hankewych M, DeSimone J. Histone deacetylase inhibitors increase p21(WAF1) and induce apoptosis of human myeloma cell lines independent of decreased IL-6 receptor expression. $\mathrm{Am} J$ Hematol. 2001;68(3):170-178.
16. Catley L, Weisberg E, Tai YT, et al. NVP-LAQ824 is a potent novel histone deacetylase inhibitor with significant activity against multiple myeloma. Blood. 2003;102(7):2615-2622.

17. Mitsiades N, Mitsiades CS, Richardson PG, et al. Molecular sequelae of histone deacetylase inhibition in human malignant B cells. Blood. 2003;101(10):4055-4062.

18. Mitsiades CS, Mitsiades NS, McMullan CJ, et al. Transcriptional signature of histone deacetylase inhibition in multiple myeloma: biological and clinical implications. Proc Natl Acad Sci U S A. 2004;101(2): 540-545.

19. Garnock-Jones KP. Panobinostat: first global approval. Drugs. 2015;75: 695-704.

20. Atadja P. Development of the pan-DAC inhibitor panobinostat (LBH589): successes and challenges. Cancer Lett. 2009;280(2): 233-241.

21. Andreu-Vieyra CV, Berenson JR. The potential of panobinostat as a treatment option in patients with relapsed and refractory multiple myeloma. Ther Adv Hematol. 2014;5(6):197-210.

22. Hideshima T, Richardson PG, Anderson KC. Mechanism of action of proteasome inhibitors and deacetylase inhibitors and the biological basis of synergy in multiple myeloma. Mol Cancer Ther. 2011;10(11): 2034-2042.

23. Ocio EM, Vilanova D, Atadja P, et al. In vitro and in vivo rationale for the triple combination of panobinostat (LBH589) and dexamethasone with either bortezomib or lenalidomide in multiple myeloma. Haematologica. 2010;95(5):794-803.

24. DeAngelo DJ, Spencer A, Bhalla KN, et al. Phase Ia/II, two-arm, openlabel, dose-escalation study of oral panobinostat administered via two dosing schedules in patients with advanced hematologic malignancies. Leukemia. 2013;27(8):1628-1636.

25. Wolf JL, Siegel D, Goldschmidt H, et al. Phase II trial of the pandeacetylase inhibitor panobinostat as a single agent in advanced relapsed/refractory multiple myeloma. Leuk Lymphoma. 2012;53(9): $1820-1823$.

26. San-Miguel JF, Richardson PG, Gunther A, et al. Phase Ib study of panobinostat and bortezomib in relapsed or relapsed and refractory multiple myeloma. J Clin Oncol. 2013;31(29):3696-3703.

27. Richardson PG, Schlossman RL, Alsina M, et al. PANORAMA 2: panobinostat in combination with bortezomib and dexamethasone in patients with relapsed and bortezomib-refractory myeloma. Blood. 2013;122(14):2331-2337.

28. Richardson PG, Schlossman RL, Alsina M, et al. Time to event analyses in PANORAMA 2: a phase 2 study of panobinostat, bortezomib, and dexamethasone in patients with relapsed and bortezomib-refractory multiple myeloma. Blood. 2013;122(21):1970.

29. San-Miguel JF, Hungria VT, Yoon S, et al. Panobinostat plus bortezomib and dexamethasone versus placebo plus bortezomib and dexamethasone in patients with relapsed or relapsed and refractory multiple myeloma: a multicentre, randomised, double-blind phase 3 trial. Lancet Oncol. 2014;15(11):1195-1206.

30. Arastu-Kapur S, Anderl JL, Kraus M, et al. Nonproteasomal targets of the proteasome inhibitors bortezomib and carfilzomib: a link to clinical adverse events. Clin Cancer Res. 2011;17(9):2734-2743.

31. Berdeja JG, Hart LL, Mace JR, et al. Phase I/II study of the combination of panobinostat and carfilzomib in patients with relapsed/refractory multiple myeloma. Haematologica. 2015;100(5):670-676.

32. Berenson JR, Hilger JD, Yellin O, et al. A phase 1/2 study of oral panobinostat combined with melphalan for patients with relapsed or refractory multiple myeloma. Ann Hematol. 2014;93(1):89-98.

33. Offidani M, Polloni C, Cavallo F, et al. Phase II study of melphalan, thalidomide and prednisone combined with oral panobinostat in patients with relapsed/refractory multiple myeloma. Leuk Lymphoma. 2012; 53(9):1722-1727.

34. Mishima Y, Santo L, Eda H, et al. Ricolinostat (ACY-1215) induced inhibition of aggresome formation accelerates carfilzomib-induced multiple myeloma cell death. Br J Haematol. 2015;169(3):423-434. 
35. Farydak ${ }^{\circledR}$ (panobinostat capsules) [prescribing information]. East Hanover, NJ: Novartis Pharmaceuticals Corporation; 2015. Available from: http://www.accessdata.fda.gov/drugsatfda_docs/ label/2015/205353s000lbl.pdf. Accessed April 15, 2015.

36. Sharma S, Beck J, Mita M, et al. A phase I dose-escalation study of intravenous panobinostat in patients with lymphoma and solid tumors. Invest New Drugs. 2013;31(4):974-985.
37. Slingerland M, Hess D, Clive S, et al. A phase I, open-label, multicenter study to evaluate the pharmacokinetics and safety of oral panobinostat in patients with advanced solid tumors and various degrees of hepatic function. Cancer Chemother Pharmacol. 2014;74(5):1089-1098.

\section{Publish your work in this journal}

The Journal of Blood Medicine is an international, peer-reviewed, open access, online journal publishing laboratory, experimental and clinical aspects of all topics pertaining to blood based medicine including but not limited to: Transfusion Medicine; Blood collection, Donor issues, Transmittable diseases, and Blood banking logistics; Immunohematology; Artificial and alternative

\section{Dovepress}

blood based therapeutics; Hematology; Biotechnology/nanotechnology of blood related medicine; Legal aspects of blood medicine; Historical perspectives. The manuscript management system is completely online and includes a very quick and fair peer-review system. Visit http://www.dovepress.com/ testimonials.php to read real quotes from published authors.

Submit your manuscript here: http://www.dovepress.com/Journal-of-blood-medicine-journal 